\title{
Bonding Characteristics of Al and Al-Alloy Strips: Processed by Severe Plastic Deformation
}

\author{
Sanjeev Sharma ${ }^{* 1}$, Rudra Pratap Singh, ${ }^{\# 2}$ Surender Kumar ${ }^{\# 3}$ \\ * Department of Mechanical Engineering, Amity University Gurgaon, Haryana, India \\ 1sanjeevs012@rediff.com

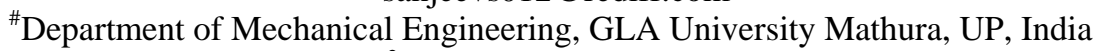 \\ 2 rudra.singh@gla.ac.in \\ ${ }^{3}$ kr.surender@gmail.com
}

\begin{abstract}
In this paper, the study of efficient bonding characteristics of AA6014 and AA1050 metal strips is carried out for Accumulative Roll Bonding (ARB) process. Among various Severe Plastic Deformation (SPD) techniques, ARB process is widely used due to its ability to produce ultra-fine grained (UFG) or nanostructured bulk material. It has been observed that, if the experimental pressure and corresponding temperature achieve their respective threshold values, then the bonding can be successfully joined as compared to the solid state welding.
\end{abstract}

Keywords- Composite Metal Sheet, Ultra-Fine Grained (UFG), Nano-Structured Material, Severe Plastic Deformation, Accumulative Roll Bonding

\section{INTRODUCTION}

Accumulative Roll Bonding (ARB) is the solid-state bonding process applied to joining similar or dissimilar metal strips by rolling. These are easy and low-cost fabrication methods for mass production of sheet metals. It is possible to fabricate ultra-fine grained (UFG) or nano-structured material products by applying the accumulative roll bonding process. Other SPD process such as Equal Channel Angular Pressing (ECAP) [1], High Pressure Torsion (HTP) [2], Cyclic Extrusion Compression (CEC) [3], Twist Extrusion (TE) [4], Continuous Confined Strip Shearing [5], and Mechanical Milling processes[6], have the following drawbacks. Firstly, the above pointed out processes are found to be improper to produce bulk materials. Secondly, the required forming dies are quite expensive, and also the required forces are very high. As compared to the above processes, ARB has no such inadequacies. In order to produce ultrafine grained bulk aluminum sheets, the ARB process was at first suggested by Saito et al. [7] then it was modified successfully by Tsuji et al. [8] by producing UFG bulk sheet of interstitial free (IF) steel, which had the average grain size less than $1 \mu \mathrm{m}$. Hongzhi et al. [9], [16] stated the development of efficient joining of Al 6111 alloy which reveals high shear strength compared to the parent alloy. The four fundamental controlling factors of the roll bonding process were annelid temperature, inlet temperature, rolling speed and the percentage of reduction. Among the above four factors, the rolling temperature was found to be the important element influencing accumulative roll bonding. Saito et al. [10] have carried out the same research with AA5083, IF steel and AA1100. The outcome shows that the strength of AA1100, increased after eight cycles, from $84 \mathrm{MPa}$ to $304 \mathrm{MPa}$, but the elongation decreased from $42 \%$ to $8 \%$. The strength of AA5083 rose from $318 \mathrm{MPa}$ to $550 \mathrm{MPa}$ after seven cycles and elongation decreased from $25 \%$ to $6 \%$, but for IF steel the strength increased to $751 \mathrm{MPa}$ from $274 \mathrm{MPa}$ after five cycles, whereas the elongation decreased from $56 \%$ to $6 \%$. Tsuji et al. [11], [17] suggested that the true strain reaches 4.0 at $200^{\circ} \mathrm{C}$, and average grain size decreases up to $280 \mathrm{~nm}$. Eizadjou et al. [12] experimentally examined the bond strength by peeling of AA1100. Also, AA1100 strips were enhanced its strength with an increase of overall reduction in thickness and temperature. Ultimately the peel strength achieved the value of base metal strength. The bond strength was increasing by increasing the rolling temperature having the constant reduction in the percentage of the thickness of bi-layered strips of two Al1100 and Al1100. The application of significant plastic deformation on two types of metals like aluminum and steel to produce the cold roll joining has used by Manesh et al. [13]. The sheet was work hardened and then annealed to attain higher ductility. It has suggested that the heat treatment of the sheets were difficult because of the growth of a brittle intermetallic compound in between $\mathrm{Al}$ and iron. The inter-metallic phase thickness strength has increased by increasing the annealing temperature having the constant duration of time. It has established by Movahedi et al. [14], [18] that better controlled anneals temperature up to $400^{\circ} \mathrm{C}$ can improve the joining strength. As a result, the above-discussed studies have concluded the experiments on grain refinement shear strength enhancement, peel strength improvement, essential controlling factors of accumulative roll bonding and increases in ductility as well as formability by annealing, but there is a need for research which has been identified on minimum bonding criteria for ARB. Therefore, the current study gave priority to find out threshold considerations for accumulative roll bonding 


\section{EXPERIMENTAL PROCEDURE}

In order to address the facts as mentioned earlier, a comprehensive experimental study is conducted with two core points, essential bonding criteria, and grain refinement with strengthening sheet metals. Annealing, the commercially pure aluminum i.e. AA1050 is soft, ductile and has the property of excellent workability and for this reason, AA1050 has selected for the present study. The aluminum-alloy i.e. AA6014 has chosen for its better structural properties from the other aluminum alloys. The chemical composition of AA1050 and AA6014 has been shown in Table 1, [15], 19].

TABLE 1. Chemical composition of Aluminiumalloys

\begin{tabular}{|c|c|c|c|c|c|c|c|c|c|c|}
\hline Al alloys & $\mathrm{Si}$ & $\mathrm{Fe}$ & $\mathrm{Cu}$ & $\mathrm{Mn}$ & $\mathrm{Mg}$ & $\mathrm{Ti}$ & $\mathrm{Ga}$ & $\mathrm{V}$ & Others & $\mathrm{Al}$ \\
\hline AA6014 & 0.773 & 0.321 & 0.137 & 0.031 & 0.586 & 0.011 & 0.008 & 0.012 & 0.121 & Balance \\
\hline AA1050 & 0.168 & 0.287 & 0.014 & 0.013 & 0.010 & 0.012 & 0.005 & 0.007 & 0.084 & Balance \\
\hline
\end{tabular}

The experiment is carried out at the temperatures $150^{\circ} \mathrm{C}$ and $500^{\circ} \mathrm{C}$. The minimum and maximum temperatures were below and upper to the re-crystallization temperature for both types of aluminum metal strips respectively. First of all, the samples of metal strips have prepared for annealing at a temperature of $400^{\circ} \mathrm{C}$; they have held for the duration of half an hour in the furnace. Then the heated samples of metal strips were cooled in the controlled furnace for 24 hours.

In the present work, roll bonding (RB) process was used for the temperature range of $200^{\circ} \mathrm{C}$ to $400^{\circ} \mathrm{C}$ with AA6014 and AA1050 sheet metals with starting thickness of $0.3 \mathrm{~mm}$ and $0.5 \mathrm{~mm}$, respectively. In order to perform the successful bonding of joining, the metal samples were preheated above as well as below the recrystallization temperature, for separate cases. The cleaning, degreasing, and wire-brushing operations were done to those surfaces of sheets to prepare them for rolling. Following the surface preparation, two metal strips having AA6014 and AA1050 have used for stacking one upon another. Then the rolling process was done.

1) Thickness reduction for fixed temperature: The underlying measurements were $20 \mathrm{~mm}$ width and $150 \mathrm{~mm}$ length for every specimen of aluminum sheets. The roll bonding analysis has begun from $200^{\circ} \mathrm{C}$ with the rate of thickness reduction starting from $1 \%$ to $20 \%$. The two metals join at the thickness reduction of $20 \%$. Again the rolling was conducted at a temperature of $250^{\circ} \mathrm{C}$ with the rate of thickness reduction between $1 \%$ and $15 \%$. Likewise, for $300^{\circ} \mathrm{C}, 350^{\circ} \mathrm{C}$, and $400^{\circ} \mathrm{C}$ the rate of thickness reduction started every time from $1 \%$ and ended at $15 \%, 10 \%$ and $5 \%$ individually, for their adequate bonding. Also, for temperatures $200^{\circ} \mathrm{C}, 250^{\circ} \mathrm{C}, 300^{\circ} \mathrm{C}, 350^{\circ} \mathrm{C}$ and $400^{\circ} \mathrm{C}$ with corresponding thickness reductions below of $20 \%, 15 \%, 10 \%$ and $5 \%$ the bonding was not done productively.

2) Accumulative Roll Bonding: In the second part of the investigation, the functional reductions have taken just like $20 \%, 15 \%$ and $5 \%$ for their comparing preheat temperatures. After the first pass has ended, the rolled samples have cut into two equivalent parts for subsequent passes. At that point, the operations of cleaning, degreasing and wire-brushing were performed before stacking and pre-heating. The sheets have rolled with specified rate of thickness reduction. Again, the rolled sheets have cut by $50 \%$ of its length. This procedure has repeated. In the second part of this experiment, the u s ed reductions have $20 \%, 15 \%$ and $5 \%$ for their corresponding preheat temperatures. When the first pass was successful, the rolled specimens have cut into two halves for subsequent passes. After this the operations of cleaning, degreasing, and wire-brushing were done before stacking and pre-heating in the furnace. The sheets have rolled considering the mentioned percentage of thickness reductions. Again, the rolled sheets have cut by $50 \%$ of its length. This process has repeated up to the third cycle of its rotation.

Surface Treatment

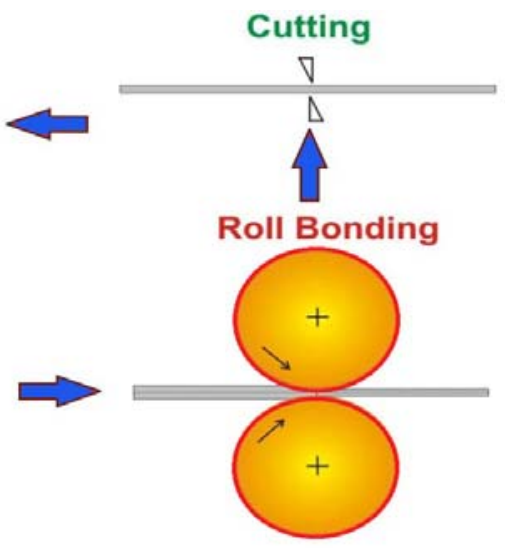

Fig. 1. Schematic diagram of various steps of Accumulative Roll-Bonding 
The schematic representation of ARB procedure has illustrated in Fig. 1, [7]. The alloy steel roller having 320 $\mathrm{mm}$ diameter, $300 \mathrm{~mm}$ length has used for this investigation and the linear surface velocity of the roll was 10 $\mathrm{m} /$ minute, in dry condition.

3) Microstructure and Strength: The metallographic tests were set up for optical microscopy by cutting, cold mounting, grinding, cleaning and etching processes. The help of an optical magnifying instrument Leica DM6000M setup has taken for finding the macrostructural image. The mean grain size has measured with intercept technique taking after the quantity of convergences of an altered test line with the grain limits taking after standard ASTM methodology. The bending test has completed in $100 \mathrm{kN}$ electro-mechanical controlled Universal Testing Machine (INSTRON 8862). The sample was set up according to ASTM particulars and loaded at a crosshead speed of $0.1 \mathrm{~mm} /$ minute. The samples have eventually fizzled after necking and break creating; then the heap versus removal was recorded for rigidity and rate of extensions were assessed.

\section{RESULT AND DISCUSSION}

It has observed that, for annealed AA6014 the ultimate strength and percentage of elongation are 172MPa and $20 \%$, and for annealed AA1050 these values are $85 \mathrm{MPa}$ and $22 \%$ respectively. Consequently, the strength is increasing with increasing number of cycles of ARB for the three sets of temperature with thickness reduction. The results are presented in Table 2. In Fig.4, individual parent metal strengths are indicated by AA6014 and AA1050 and then these have combined into $215 \mathrm{MPa}$, for the first cycle single pass in roll bonded condition for preheating temperature as $200^{\circ} \mathrm{C}$ with $20 \%$ reduction of thickness. After the third pass, the strength becomes as the maximum value of $272 \mathrm{MPa}$ for $200^{\circ} \mathrm{C}$ in multilayered AA6014/AA1050 composite. The values of average strengths are $205 \mathrm{MPa}, 230 \mathrm{MPa}$, and $245 \mathrm{MPa}$ for first, second and third cycle respectively for the temperature of $300^{\circ} \mathrm{C}$ and $15 \%$ thickness reduction combination is indicated by the marked line.
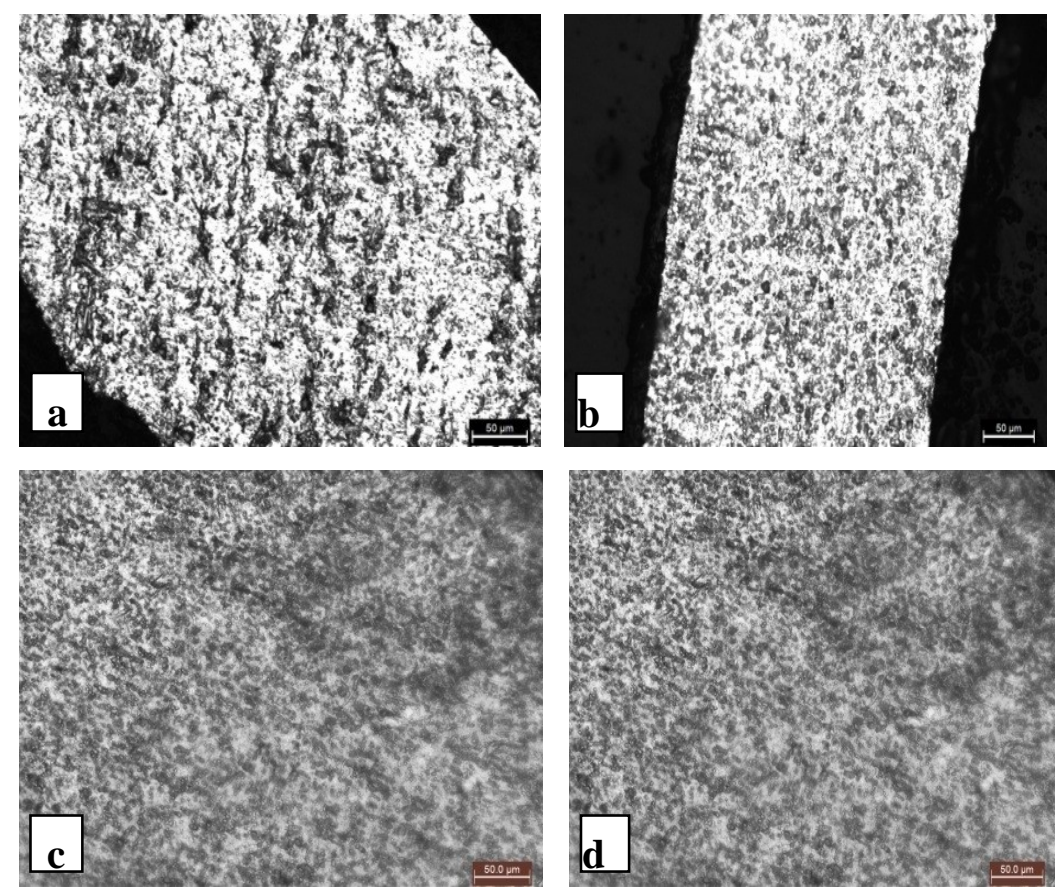

Fig. 2 Optical micrograph of parent and ARB metals for $20 \%$ reduction and $200^{\circ} \mathrm{C}$ preheat temperature(a) Fully annealed parent metal AA1050, (b) Fully annealed parent metal AA6014, (c) AA1050 after 3rd cycle and (d) AA6014 after 3rd cycle.

It has apparently been observed and shown in Fig.2 and Fig. Three that successful bonding between two metal strips can be achieved with the parametric combination of reduction of thickness in the average elongation of parent metals are designated with AA1050, AA6014 and are transformed to 12\%, 10\% and 9\% elongation for the first, second and third cycle of ARB, respectively, as shown in Fig. 5. 


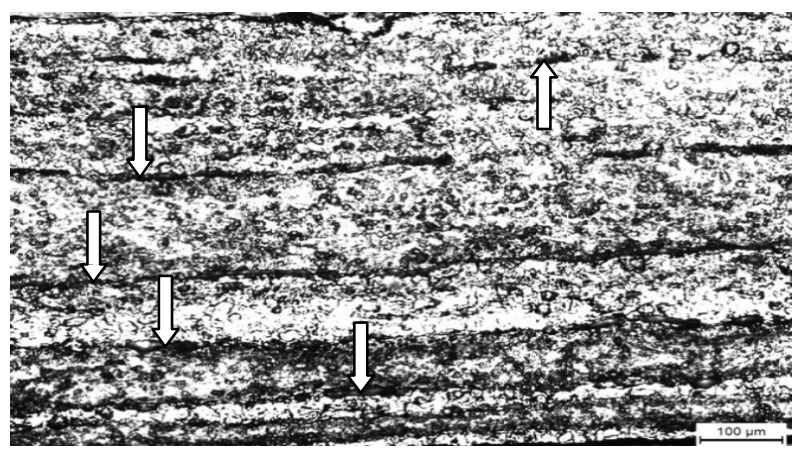

Fig. 3. Optical micrograph of roll bonded sheet after the third pass

The percentage of elongation is decreasing with cycle by cycle, which has identified with other two temperatures, in the same figure. But it is increasing with increasing preheat temperature for a fixed number of cycle.

TABLE 2. Average strength and average percentage of elongation after ARB of multi-layered AA6014/AA1050 composite

\begin{tabular}{|l|l|l|l|l|l|l|}
\hline & \multicolumn{2}{|c|}{$1_{\text {st }}$ Cycle } & \multicolumn{2}{c|}{$2_{\text {nd }}$ Cycle } & \multicolumn{2}{c|}{$3_{\text {rd }}$ Cycle } \\
\cline { 2 - 7 } & $\begin{array}{l}\text { UTS } \\
\text { (MPa) }\end{array}$ & $\begin{array}{l}\text { Elongation } \\
\text { in \% }\end{array}$ & $\begin{array}{l}\text { UTS } \\
\text { (MPa) }\end{array}$ & $\begin{array}{l}\text { Elongation } \\
\text { in \% }\end{array}$ & $\begin{array}{l}\text { UTS } \\
(\mathrm{MPa})\end{array}$ & $\begin{array}{l}\text { Elongation } \\
\text { in \% }\end{array}$ \\
\hline $\begin{array}{l}200^{0} \mathrm{C} \& 20 \% \\
\text { reduction }\end{array}$ & 215 & 10 & 260 & 9 & 272 & 8 \\
\hline $\begin{array}{l}300^{\circ} \mathrm{C} \& 15 \% \\
\text { reduction }\end{array}$ & 205 & 11 & 230 & 10 & 245 & 9 \\
\hline $\begin{array}{l}400^{0} \mathrm{C} \& 5 \% \\
\text { reduction }\end{array}$ & 200 & 16 & 220 & 14 & 235 & 11 \\
\hline
\end{tabular}

The lowest average strength is $200 \mathrm{MPa}$ for the last combination of temperature $400^{\circ} \mathrm{C}$ and $5 \%$ of reduction, but it increases with increasing number of cycles, as $200 \mathrm{MPa}$ for the second cycle and $235 \mathrm{MPa}$ for the third cycle, can be identified with the marked line as shown in Fig.4. Consequently, the strength is increasing with increasing number of cycles of ARB for each pass and preheats temperature of five restrictive conditions.

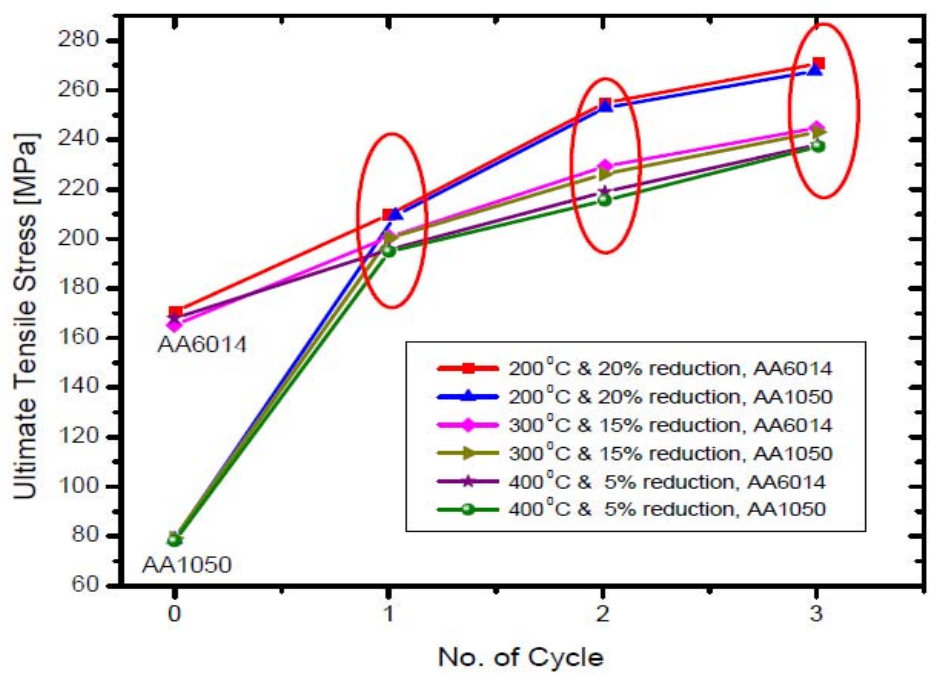

Fig.4. The average tensile strength of parent metals before rolling and after ARB, versus no of cycles

The threshold parameters of bonded samples have accordingly indicated in Table 3. The dot marks having such parameters canton join the AA6014 and AA1050 metallic strip successfully, while the left side of dot marks, the strong bond has not achieved. The outcome reveals that low preheat temperature with high reduction rate and high preheat temperature with low reduction rate combinations can create sufficient bonding. It is also 
established that the combination of low preheat temperature with a low percentage of thickness reduction is not capable of resulting in successful bonding. To fabricate successful bonding, minimum energy is essential to overcome the initial energy obstruction. This minimum necessary energy can be supplied by rising rolling temperature or by external force followed by general conventional mechanical processes like pressing, hammering, rolling or forging. The percentage of thickness reduction is similar to that of the applied forces, in rolling. The combination of applied force and the preheat temperature contribute the required energy for the successful bonding. In this study, the key factors like pre-heat temperature and threshold percentage of thickness reduction govern the successful bonding.

TABLE 3. Marks sufficient preheat temperature for Bonding on rolling

\begin{tabular}{|c|c|c|c|c|c|}
\hline \multirow{2}{*}{$\begin{array}{c}\text { Limiting } \\
\text { thickness } \\
\text { reduction }\end{array}$} & \multicolumn{5}{|c|}{ Preheat temperature } \\
\cline { 2 - 6 } & $200^{\circ} \mathrm{C}$ & $250^{\circ} \mathrm{C}$ & $300^{\circ} \mathrm{C}$ & $350^{\circ} \mathrm{C}$ & $400^{\circ} \mathrm{C}$ \\
\hline $20 \%$ & $\bullet$ & $\bullet$ & $\bullet$ & $\bullet$ & $\bullet$ \\
\hline $15 \%$ & & $\bullet$ & $\bullet$ & $\bullet$ & $\bullet$ \\
\hline $10 \%$ & & & & & $\bullet$ \\
\hline $5 \%$ & & & & & $\bullet$ \\
\hline
\end{tabular}

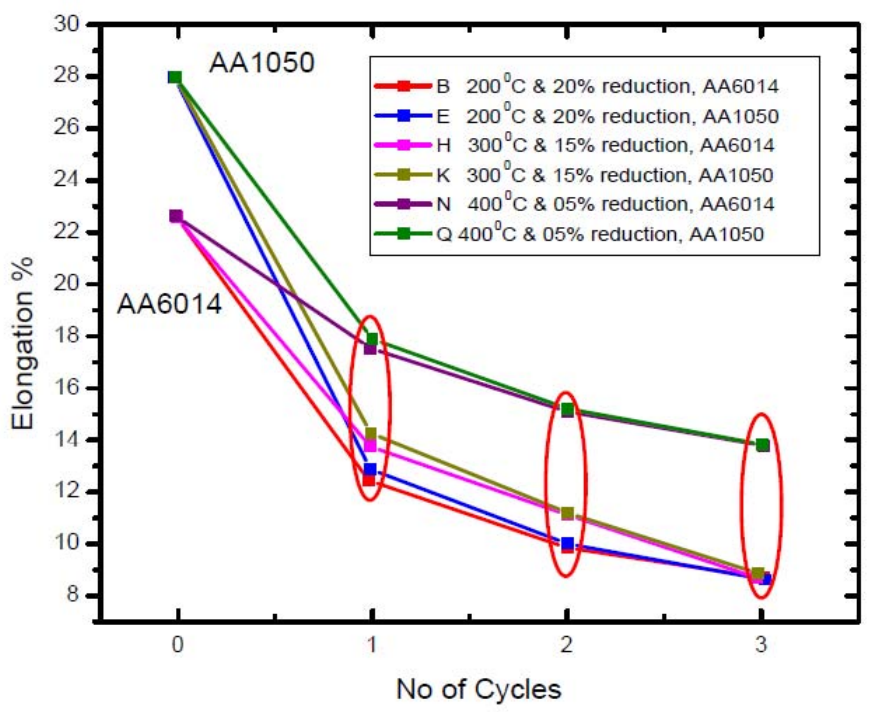

Fig.5. The average elongation in \% of parent metals before rolling and after ARB, versus no of cycles

\section{CONCLUSION}

In the current study, it has been seen that after the third cycle at $200^{\circ} \mathrm{C}$ preheat temperature with $20 \%$ thickness reduction, the average grain size transforms to $8 \mu \mathrm{m}$ and $10 \mu \mathrm{m}$ for AA6014 and AA1050, respectively; whereas, the mean grain size of fully annealed parent metals are $20 \mu \mathrm{m}$ and $30 \mu \mathrm{m}$, respectively. For that reason, it should illustrate the repercussion that grain refinement takes place in ARB process. By the grain refinement, the strength attains the greatest value as $272 \mathrm{MPa}$ which is 1.6 and 3.4 times better than the strength of parent metals AA6014 and AA1050, respectively. In the same way, ductility reduces with increasing of cycle numbers. The current study also investigates the best parameters of minimum joining. For that reason, the preheat temperature and equivalent thickness reduction have created a substantial effect on solid-state bonding in the area of hot rolling which contributes the threshold parameters for bonding of AA6014 and AA1050 strips.

\section{ACKNOWLEDGEMENT}

The Principal Author is very thankful to Prof. P. B. Sharma, Vice Chancellor Amity University Haryana, for his kind support and motivation. 


\section{REFERENCES}

[1] V.M. Segal, "Equal channel angular extrusion: from macro mechanics to structure formation,” Materials Science and Engineering A: vol. 271(1), pp. 322-333, 1 Nov. 1999.

[2] A. Zhilyaev, T. Langdon, "Using high-pressure torsion for metal processing: Fundamentals and applications" Progress in Materials Science, vol. 53(6), pp. 893-979, 2008.

[3] O.N. Senkov, S.V. Senkova, J.M. Scott, D.B. Miracle, "Compaction of amorphous aluminum alloy powder by direct extrusion and equal channel angular extrusion,” Materials Science and Engineering: A, 393 vol. (1-2), pp.12-21, Feb. 2005

[4] J.C. Lee, H.K. Seok and J.Y. Shu, “ Bulk nanostructured metals by severe plastic deformation”, Acta Mater, vol.50, pp. 4005-4019, 2002.

[5] B. Ratna Sunil, "Repetitive corrugation, and straightening of sheet metals". Materials and Manufacturing Processes, vol. 30(10), pp. 1262-1271, 2015.

[6] Takacs and Laszlo, "Self-sustaining reactions induced by ball milling," Progress in Materials Science, vol.47 (4), pp.355-414. Jan 2002.

[7] Y. Saito, N. Tsuji, H. Utsunomiya, T. Sakai, R.G. Hong, Ultra-Fine Grained Bulk Aluminum Produced By Accumulative RollBonding (ARB) Process, Scripta Materialia, Vol. 39, No. 9, pp. 1221-1227, 1998.

[8] N. Tsuji, Y. Saito, H. Utsunomiya, S. Tanigawa, "Ultra-fine-grained bulk steel produced by Accumulative roll-bonding (ARB) process,” Scripta Materialia, Vol. 40, No. 7, pp. 795-800, 1999.

[9] Y. Hongzhi, and J.G. Lenard, “A study of warm and cold roll-bonding of an aluminum alloy,” Material Science and Engineering: A, Vol.385, pp.419-428, 2004.

[10] Y. Saito, Utsunomiya, N. Tsuji, T. Sakai, "Novel ultra-high straining process for bulk Materials of the development of the accumulative roll- bonding (ARB) process,” Acta Materialia, Vol. 47, No. 2, pp. 579-583,1999.

[11] N. Tsuji, K. Shiotsuki, Y. Saito, "Super plasticity of UFG Al-Mg alloy produced by ARB, Materials Transactions," The Japan Institute of Metals and Materials, Vol. 40, No. 8, pp.765-771, 1999.

[12] M. Eizadjou, H. D. Manesh, K. Janghorban, "Investigation of roll bonding between aluminum alloy strips,” Materials and Design, Vol. 29, pp. 909-913, 2008.

[13] H.D. Manesh, and A.K. Taheri, "Bond strength and formability of an aluminum clad steel sheet", Journal of Alloys and Compounds, Vol. 361, pp.138-143.2003.

[14] M. Movahedi, H.R. Madaah-Hosseini, A.H. Kokabi, "The influence of roll bonding parameters on the bond strength of Ai-3003/Zn soldering sheets," Material Science and Engineering A, Vol487,pp.417-423, 2008.

[15] S. Suprim, M. Atanu, K.P. Surjya, B.S. Shiv, 5th International Conference, AIMTDR, IIT Guwahati, Assam, pp. 610-616, 2014.

[16] F. Kümmel, M. Kreuz, T. Hausöl, H. W. Höppel, M. Göken, Microstructure and Mechanical Properties of Accumulative Roll-Bonded AA1050A/AA5005 Laminated Metal Composites, Metals, Vol.56(6), pp. 123-129, 2016.

[17] A. Kobler, T. Beuth, T. Klöffel, R. Prang, M. Moosmann, T. Scherer, S. Walheim, H. Hahn, C. Kübel, B. Meyer, T. Schimmel, E. Bitzek, “Nanotwinned silver nanowires, Structure and mechanical properties”, Acta Mater, Vol.92, pp.299-308, 2015.

[18] M. Ruppert, H.W. Höppel, M. Göken, "Influence of cross-rolling on the mechanical properties of an accumulative roll bonded aluminum alloy AA6014”, Mater. Sci. and Eng. A, Vol. 597, pp.122-127, 2014.

[19] J. Ast, K. Durst, "Nan forming behaviour and macrostructural evolution during nanoimprinting of ultrafine-grained and nanocrystalline metals”, Mater. Sci. Eng. A, Vol.568, pp.68-75, 2013.

\section{AUTHOR PROFILE}

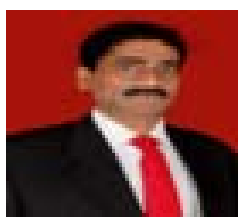

Mr. Sanjeev Sharma working as Associate Professor, Department of Mechanical Engineering, Amity University Gurgaon, Haryana. He did Bachelor degree from Mechanical Engineering, STB College of Engineering Tuljapur (Govt. Engineering College) in 1994 and Master's degree in Thermal Engineering from Institute of Engineering and Technology, Dr. B R Ambedkar University Campus, Agra. He has eighteen years of teaching \& Research experience and participated in various programs organized by prestigious institutions like CII, FICCI, ASOCHEM, PHD Chamber, DST, Govt of India. He was associated with DRDO research project in 2010 for Characterization of Nanostructured material processed by severe plastic deformation in Dayalbagh Engineering College Agra. He has published several research papers in National and International reputed journals. In 2009 he joined research fellow program at IIT Delhi.

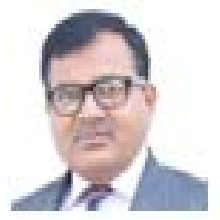

Dr. Rudra Pratap Singh working as Associate Professor in Mechanical Engineering Department, Institute of Engineering and Technology, G.L.A.University, Mathura U.P. having Teaching Experience of More than sixteen years also having Industrial Experience of Six years and Five months in the engineering field. He has earned $\mathrm{Ph}$. D. Degree from DTU Dehradun in 2015. He has published several research papers in National and International reputed journals.

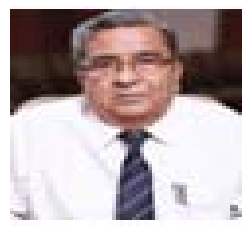

Prof. Surender Kumar currently honoured as President of Indo-US Research Institute for Sustainable Development, California, USA. He was also served as Professor and Dean Research in GLA University Mathura, and BITS Ranchi. He has published several research papers in National and International reputed journals and Supervise sixteen Ph.D. 